\title{
Differentiation of Dental Pulp Stem Cells into Neuron-Like Cells in Serum-Free Medium
}

\author{
Shahrul Hisham Zainal Ariffin, ${ }^{1}$ Shabnam Kermani, ${ }^{1}$ \\ Intan Zarina Zainol Abidin, ${ }^{1}$ Rohaya Megat Abdul Wahab, ${ }^{2}$ Zulham Yamamoto, ${ }^{1}$ \\ Sahidan Senafi, ${ }^{1}$ Zaidah Zainal Ariffin, ${ }^{3}$ and Mohamad Abdul Razak ${ }^{4}$ \\ ${ }^{1}$ School of Biosciences and Biotechnology, Faculty of Science and Technology, Universiti Kebangsaan Malaysia, \\ 43600 Bangi, Selangor, Malaysia \\ ${ }^{2}$ Department of Orthodontics, Faculty of Dentistry, Universiti Kebangsaan Malaysia, Jalan Raja Muda Abdul Aziz, \\ 50300 Kuala Lumpur, Malaysia \\ ${ }^{3}$ School of Biology, Faculty of Applied Science, Universiti Teknologi MARA, 40450 Shah Alam, Selangor, Malaysia \\ ${ }^{4}$ Allianze University College of Medical Sciences, Waziria Medical Square, Jalan Bertam 2, 13200 Kepala Batas, \\ Penang, Malaysia
}

Correspondence should be addressed to Shahrul Hisham Zainal Ariffin; shahroy8@gmail.com

Received 13 December 2012; Revised 23 September 2013; Accepted 7 October 2013

Academic Editor: Deepa Bhartiya

Copyright (C) 2013 Shahrul Hisham Zainal Ariffin et al. This is an open access article distributed under the Creative Commons Attribution License, which permits unrestricted use, distribution, and reproduction in any medium, provided the original work is properly cited.

\begin{abstract}
Dental pulp tissue contains dental pulp stem cells (DPSCs). Dental pulp cells (also known as dental pulp-derived mesenchymal stem cells) are capable of differentiating into multilineage cells including neuron-like cells. The aim of this study was to examine the capability of DPSCs to differentiate into neuron-like cells without using any reagents or growth factors. DPSCs were isolated from teeth extracted from 6- to 8-week-old mice and maintained in complete medium. The cells from the fourth passage were induced to differentiate by culturing in medium without serum or growth factors. RT-PCR molecular analysis showed characteristics of $C d 146^{+}$, $C d 166^{+}$, and $C d 31^{-}$in DPSCs, indicating that these cells are mesenchymal stem cells rather than hematopoietic stem cells. After 5 days of neuronal differentiation, the cells showed neuron-like morphological changes and expressed MAP2 protein. The activation of Nestin was observed at low level prior to differentiation and increased after 5 days of culture in differentiation medium, whereas Tub3 was activated only after 5 days of neuronal differentiation. The proliferation of the differentiated cells decreased in comparison to that of the control cells. Dental pulp stem cells are induced to differentiate into neuron-like cells when cultured in serum- and growth factor-free medium.
\end{abstract}

\section{Introduction}

Dental pulp tissue contains many types of cells including committed cells (e.g., endothelial cells) and uncommitted cells (i.e., DPSCs). DPSCs are of mesenchymal stem cells (MSCs) [1]. In mice, the majority of MSCs were isolated from bone marrow [2] and peripheral blood [3, 4]. These MSCs can be characterized by the expression of specific gene markers such as $C D 44, C D 73, C D 90, C D 105, C D 117$, and $C D 166[5,6]$.

DPSCs are capable of differentiating into multilineage cells [7-9] including neuron-like cells [10]. Neuron-like cells differentiated from MSCs derived from bone marrow cells
[11-13] and brain [14]. However, MSCs derived from dental pulp, that is, DPSCs, are also capable of differentiating into neuron-like cells [10]. The characteristics of MSCs from bone marrow are similar to those cells derived from dental pulp [11]. Both types of MSCs express Cd44, Cd106, Cd146, and Cd166 [15-17].

Many factors are involved in neuronal differentiation including nestin [18], tubulin3 (Tub3) [19], and MAP2 [20]. Nestin is involved in the radial growth of axons during neuronal differentiation in vertebrate cells $[19,21]$. Therefore, Nestin is known as a neural marker and its presence can be considered as a criterion for the ability to differentiate 
TABLE 1: Primers involved in RT-PCR experiments.

\begin{tabular}{|c|c|c|c|c|}
\hline Gene/accession no. & Primers & Sequences & Expected product size (bp) & Annealing temperature $\left({ }^{\circ} \mathrm{C}\right)$ \\
\hline \multirow{2}{*}{ Cd146 (NM_023061) } & Forward & $5^{\prime}$-GGACCTTGAGTTTGAGTGG-3' & \multirow{2}{*}{479} & \multirow{2}{*}{60} \\
\hline & Reverse & 5'-CAGTGGTTTGGCTGGAGT-3' & & \\
\hline \multirow{2}{*}{ Cd166 (NM_009655) } & Forward & $5^{\prime}$-AACATGGCGGCTTCAACG-3' & \multirow{2}{*}{630} & \multirow{2}{*}{61} \\
\hline & Reverse & $5^{\prime}$-GACGACACCAGCAACGAG-3' & & \\
\hline \multirow{2}{*}{ Nestin (NM_016701) } & Forward & $5^{\prime}$-CGCTCGGGAGAGTCGCTT-3' & \multirow{2}{*}{215} & \multirow{2}{*}{64} \\
\hline & Reverse & $5^{\prime}$-CCAGTTGCTGCCCACCTTC-3' & & \\
\hline \multirow{2}{*}{ Gapdh (NM_008084) } & Forward & $5^{\prime}$-CAACGGCACAGTCAAGG-3’ & \multirow{2}{*}{717} & \multirow{2}{*}{62} \\
\hline & Reverse & $5^{\prime}$-AAGGTGGAAGAGTGGGAG-3' & & \\
\hline \multirow{2}{*}{ Tub3 (NM_023279) } & Forward & $5^{\prime}$-ACGCATCTCGGAGCAGTT-3' & \multirow{2}{*}{125} & \multirow{2}{*}{61} \\
\hline & Reverse & $5^{\prime}$-CGGACACCAGGTCATTCA-3' & & \\
\hline \multirow{2}{*}{ Cd31 (NM_001032378.1) } & Forward & $5^{\prime}$-GGTCTTGTCGCAGTATCAG-3' & \multirow{2}{*}{355} & \multirow{2}{*}{58} \\
\hline & Reverse & 5'-ATGGCAATTATCCGCTCT-3' & & \\
\hline
\end{tabular}

into neurons $[18,22]$. However, Nestin has shown to be expressed by other cell types such as hair follicle stem cells [23], pericytes [24], endothelial cells [25], myofibroblasts, and pancreatic fibroblasts [26]. Therefore, analysis on expression of other specific neuron markers such as Tub3 [27, 28] and MAP2 $[29,30]$ has been done concurrently for neuronal confirmation. Tub3 and MAP2 play a role in the stability of axons and neuronal cell bodies [20,31]. Certain growth factors, such as epidermal growth factor, basic fibroblast growth factor, and retinoic acid, were used for neuronal induction [32-35]. Dimethyl sulfoxide (DMSO) was also used to induce transformation of MSCs into neuron-like phenotypes in vitro $[12,13]$. The objective of the present study was to examine the directed differentiation of DPSCs into neuron-like cells in the absence of chemical induction.

\section{Materials and Methods}

2.1. Isolation of Dental Pulp Cells. Incisor teeth were extracted from 6- to 8-week-old mice under sterile conditions and placed in medium containing $1 \mathrm{X}$ PBS (Sigma, USA). The extracted dental pulp was washed with 1X PBS containing $1 \%$ $(\mathrm{v} / \mathrm{v})$ penicillin-streptomycin (Invitrogen, USA).

Dental pulp tissue was incubated for 1 hour in 4 -unit collagenase type I at $37^{\circ} \mathrm{C}$, followed by several rounds of enzymatic disaggregation. The cells were centrifuged at $1200 \mathrm{~g}$ for 10 minutes at $25^{\circ} \mathrm{C}$ and cultured in complete medium consisting of $\alpha$-MEM (Invitrogen, USA) supplemented with $20 \%(\mathrm{v} / \mathrm{v})$ FBS (Biowest, USA) and $1 \%(\mathrm{v} / \mathrm{v})$ penicillinstreptomycin. The cells $1 \times 10^{5}$ cells $/ \mathrm{mL}$ obtained were put in a T25 flask containing complete medium and cultured in an incubator with $5 \% \mathrm{CO}_{2}$ atmosphere and $95 \%$ humidity at $37^{\circ} \mathrm{C}$.

After 24 hours, the suspended cells were removed from the medium, and the flask was washed with 1X PBS solution. The cells were grown in complete medium until 80\% confluency. A solution of $0.25 \%(\mathrm{v} / \mathrm{v})$ trypsin-EDTA (Sigma, USA) was used to detach the dental pulp cells from the flask surface for subculturing in another flask at $1 \times 10^{5}$ cells $/ \mathrm{mL}$. For cryopreservation and storage, cells at the fourth passage were placed in cryovials containing freezing medium consisting of $\alpha$-MEM, $10 \%(\mathrm{v} / \mathrm{v})$ DMSO (Sigma, USA), and 50\% (v/v) FBS and stored in liquid nitrogen. In this study, the cells used were at the fourth passage.

\subsection{Differentiation of Dental Pulp Stem Cells into Neuronal} Cells. Approximately $1 \times 10^{5}$ cells were transferred into 24 well plates containing complete medium and were allowed to grow for 24 hours until adherence. The medium was discarded, and the cells were washed with PBS. The cells were then cultured in serum- and growth factor free-medium consisting of $\alpha$-MEM and 1\% (v/v) penicillin-streptomycin for 5 days. The medium was changed every 2-3 days during this 5-day period. As a control, the same number of cells was cultured in complete medium (consists of $\alpha$-MEM, $1 \%(\mathrm{v} / \mathrm{v})$ penicillin-streptomycin, and $15 \%(\mathrm{v} / \mathrm{v})$ fetal bovine serum) for 5 days. Cell morphology was monitored on days 2 and 5 of neuronal differentiation using an Olympus phase-contrast microscope.

2.3. Molecular Analysis Using RT-PCR. Control and differentiated cells were detached using $0.25 \%(\mathrm{v} / \mathrm{v})$ trypsin-EDTA and centrifuged at $1400 \mathrm{~g}$ for 10 minutes. Total RNA was extracted using TRI-reagent (Sigma, USA) according to the manufacturer's protocol. The purity of the total RNA was assessed spectrophotometrically at 260 and $280 \mathrm{~nm}$, with an $\mathrm{A}_{260}: \mathrm{A}_{280}$ ratio of 1.8-2.0 considered acceptable. Approximately, $300 \mathrm{ng}$ of total RNA sample was used for each RT-PCR reaction with the Access Quick RT-PCR system kit (Promega, USA). The primers were designed using the Primer Premier 5.0 software program based on sequences obtained from NCBI. Information on the primers is summarized in Table 1.

Primary cDNA synthesis was performed using AMV reverse transcriptase for 45 minutes at $45^{\circ} \mathrm{C}$ followed by deactivation for 2 minutes at $94^{\circ} \mathrm{C}$. The amplification consisted of denaturation for 30 seconds at $94^{\circ} \mathrm{C}$, annealing for 60 seconds, and extension for 60 seconds at $68^{\circ} \mathrm{C}$, performed for 40 cycles. A final extension step was performed for 7 minutes at $68^{\circ} \mathrm{C}$. The amplified products were separated using 
$1 \%(\mathrm{w} / \mathrm{v})$ agarose gel electrophoresis, stained, and analysed. The amplified products were subjected to DNA sequencing and verified using the BLASTN program from NCBI. As for expression level analysis, a total of $1 \mu \mathrm{g}$ of total RNA was used for each amplification and intensity was determined using online ImageJ 1.47 program (http://rsbweb.nih.gov/ij/).

2.4. Immunocytochemistry of MAP2. The induced neuronal cells were washed with IX PBS and fixed at $4^{\circ} \mathrm{C}$ with $4 \%$ $(\mathrm{v} / \mathrm{v})$ paraformaldehyde for 2 hours. The cells were washed 3 times with $0.05 \%$ PBS-Tween 20 followed by $2 \%$ PBS-Triton$\mathrm{X}$ for 10 minutes. Then, the cells were washed again 3 times with $0.05 \%$ PBS-Tween 20 . The cells were incubated at $37^{\circ} \mathrm{C}$ with $10 \%$ goat serum diluted in $0.05 \%(\mathrm{v} / \mathrm{v})$ PBS-Tween 20 plus $0.01 \mathrm{mg} / \mathrm{mL}$ BSA for 30 minutes prior to incubation of primary antibody. This solution was removed and primary antibody at 1:200 diluted with $0.05 \%(\mathrm{v} / \mathrm{v})$ PBS-Tween 20 plus $3 \%(\mathrm{v} / \mathrm{v})$ goat serum and $1 \mathrm{mg} / \mathrm{mL}$ BSA were added for 24 hours at $4^{\circ} \mathrm{C}$. Then, the cells were washed 3 times with $0.05 \%(\mathrm{v} / \mathrm{v})$ PBS-Tween 20 followed by incubation of secondary antibody anti-mouse IgG-FITC for 30 minutes at room temperature diluted at 1:50 with Tween 20 plus $3 \%(\mathrm{v} / \mathrm{v})$ goat serum and $1 \mathrm{mg} / \mathrm{mL}$ BSA. Finally, the cells were washed 3 times with $0.05 \%(\mathrm{v} / \mathrm{v})$ PBS-Tween 20 prior to analysis using fluorescence microscope. Negative control used was undifferentiated cells without neuronal induction, that is, cultured in complete medium.

2.5.3-(4,5-Dimethylthiazol-2-yl)-2,5-diphenyltetrazolium Bromide (MTT) Assay. Approximately $1 \times 10^{4}$ cells were seeded in 96-well plates and incubated for 24 hours at $37^{\circ} \mathrm{C}$. Two groups of cells were cultured: one in complete medium (control) and the other in serum- and growth factor-free medium. After, 24-hour incubation, approximately $20 \mu \mathrm{L}$ MTT $(5 \mathrm{mg} / \mathrm{mL})$ was added to each sample and the samples were incubated for another $4 \mathrm{~h}$ at $37^{\circ} \mathrm{C}$. The mixture was slowly removed, $200 \mu \mathrm{L}$ of DMSO was added to each well, and the wells were measured by an ELISA Plate Reader at $570 \mathrm{~nm}$. Each experiment was repeated in triplicate. The cells were subjected to MTT assay on the first, third, and fifth days of neuronal induction. The number of viable cells for each analysis was determined using a standard graph created prior to the experiment.

2.6. Statistical Analysis. Data from the differentiated and control groups were compared using paired $t$-test in SPSS program version 16.0.2. Differences with a $P$ value $<0.05$ were considered statistically significant. Data obtained were presented as average (mean $\pm \mathrm{SD}$; standard deviation) from three independent experiments $(n=3)$.

\section{Results}

3.1. Identification of Mesenchymal Stem Cells in Dental Pulp Tissue. The identity of dissociated cells isolated from dental pulp tissue using collagenase was confirmed by their capacity to form adherent colonies consisting of sphere-like clusters of cells (Figure 1). Averages of $6.8 \times 10^{4}$ cells $/ \mathrm{cm}^{2}$ were found capable to obtain colonies after 24 hours cultured in the complete medium. Then, the suspended cells were discarded and only adherent cells were expanded in the medium. The suspended cells may have been cells that were unable to survive in the medium. The colonies began to change their shape during the second passage. The cells assumed a fibroblast-like morphology with a long, thin body during the fourth passage and became confluent after 2 to 3 days of in vitro culture in complete medium.

Molecular analysis was performed to validate the types of cells in the fourth passage. The total RNA was extracted from the fourth passage of dental pulp cells and was subjected to RT-PCR analysis (Figure 2). This analysis showed Cd146 and Cd166 amplicons in these cells, whereas activation of $C d 31$ was not observed. The amplicon of Gapdh was found in dental pulp cells both before and after differentiation. Analysis of expression level for $C d 146$ and $C d 166$ was shown to produce $118.0 \pm 16.8 \%$ and $77.5 \pm 14.3 \%$, respectively, when compared to Gapdh (100\%) which was used to normalize the cellular mRNA level.

3.2. Morphological Changes into Neuron-Like Cells and Expression of MAP2 Protein. After 5 days of culture, most of the cells showed a morphological change to a long, thin body shape (Figure 3 ). The cytoplasm was contracted toward the nucleus and assumed a multipolar shape. The cells displayed small, spherical, and contracted bodies and a conical cytoplasm with branches resembling the neuronal perikaryon, axon, and dendrite. The perikaryon, dendrite, and axon of a neuronal cell are indicated, respectively, by a white arrow, an open arrowhead, and a black arrow. Approximately 60\%$70 \%$ of the cell population differentiate into neuron-like cells, an indication that differentiation occurred due to the absence of serum and growth factors but not because of spontaneous differentiation. DPSCs expressed the neuronspecific protein marker MAP2 after 5 days of culture in serum- and growth factor-free medium (Figure 3). However MAP2 was not detected in DPSCs or undifferentiated cells without neuronal induction, that is, cultured in complete medium (negative control) (Figure 3).

3.3. Activation of Neuronal Markers. The cells showed expression of $C d 146^{+}, C d 166^{+}$, and $C d 31^{-}$before differentiation. RT-PCR analysis showed the presence of a Nestin amplicon $(\sim 215 \mathrm{bp})$ in the cells, both before and after differentiation. However, the intensity of Nestin activation was significantly higher after differentiation compared with before differentiation (Figure 4(a)). An amplicon of Tub3 ( 125 bp) was observed after day 5 of neuronal differentiation (Figure 4(b)). Tub3 was shown to be activated after 5 days of neuronal differentiation. Gapdh was used as a positive control both before and after differentiation. A Gapdh amplicon ( 717 bp) was found in cells both before and after differentiation, indicating that Gapdh remains activated in both types of cells (Figure 4(c)).

3.4. Proliferation of Dental Pulp Stem Cells during Differentiation. Cell viability studies were performed to assess 


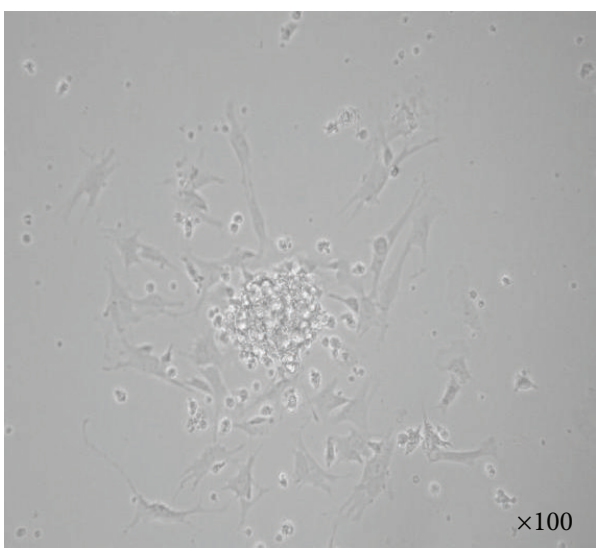

(a)

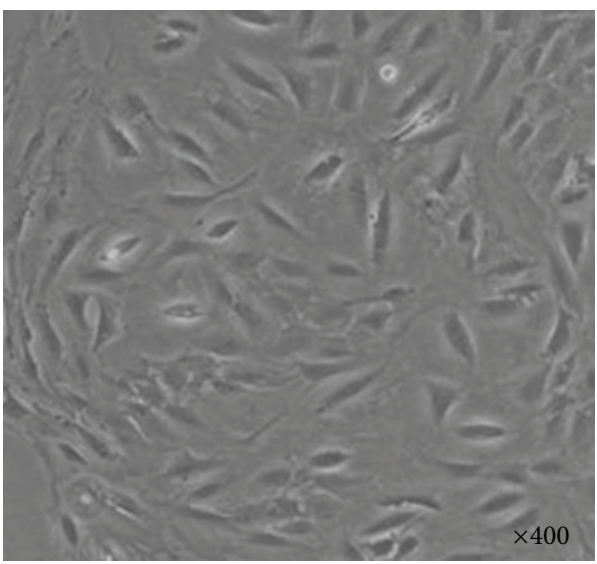

(c)

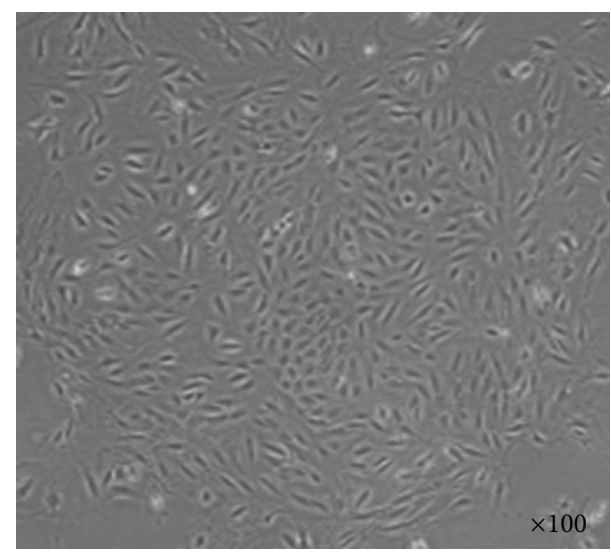

(b)

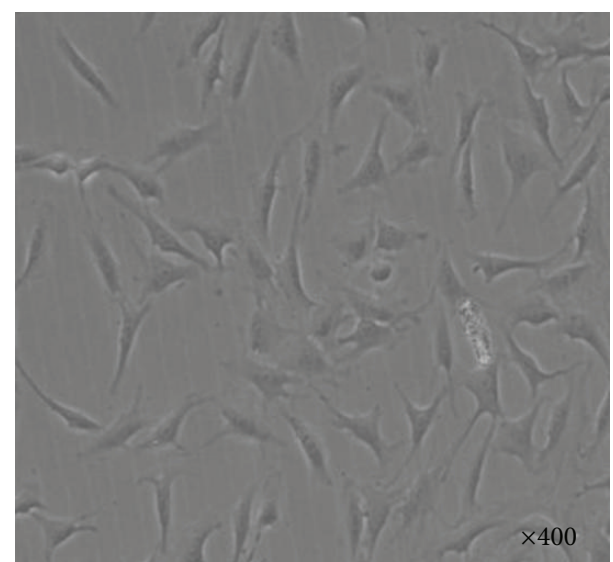

(d)

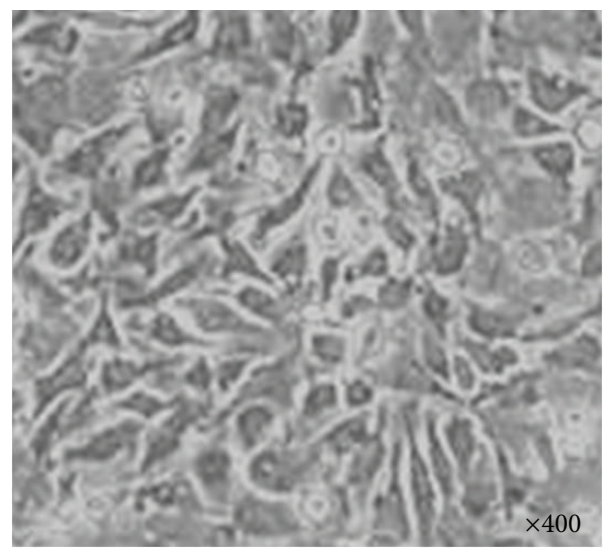

(e)

FIGURE 1: Characteristics of isolated and in vitro mouse dental pulp stem cells. Colonies derived from dental pulp at the first passage (a) and after 24 hours of culture (b). Colonies began to show changes in shape after the second passage (c), a fibroblastic cell shape after the fourth passage (d), and confluence after 2-3 days of culture in complete medium (e).

the proliferation capacity of both differentiated and undifferentiated cells during neuronal differentiation. The numbers of control and differentiated cells were significantly $(P<0.05)$ increased upon differentiation compared with day 0 of culture (Figure 5). However, the proliferation capacity of the cells began to change gradually after 24 hours of culture until day
5 of neuronal differentiation, with the number of control cells remaining higher. Both types of cells maintained their growth rate during the initial 24 hours, of culture. However, the differentiated cells showed a reduction of growth rate after 24 hours whereas the undifferentiated (control) cells maintained their growth rate, resulting in an increased number of viable 


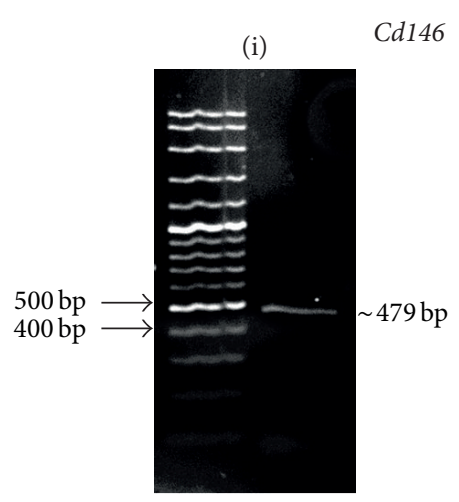

(i) Undifferentiated cells

(ii) Differentiated cells

(a)

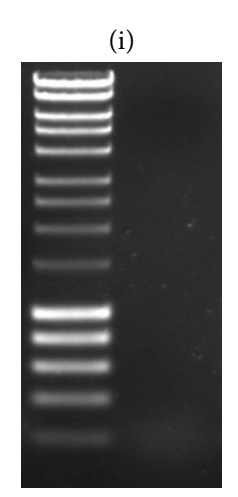

Cd31

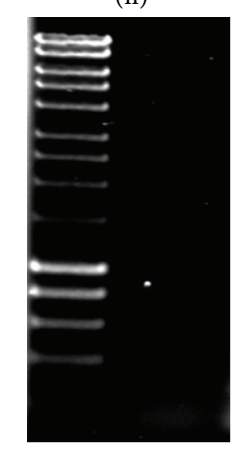

(i) Undifferentiated cells

(ii) Differentiated cells

(c) (ii)

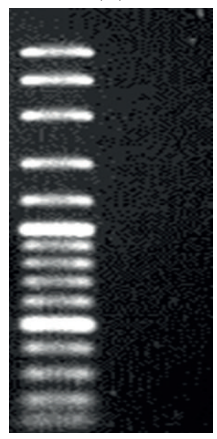

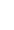

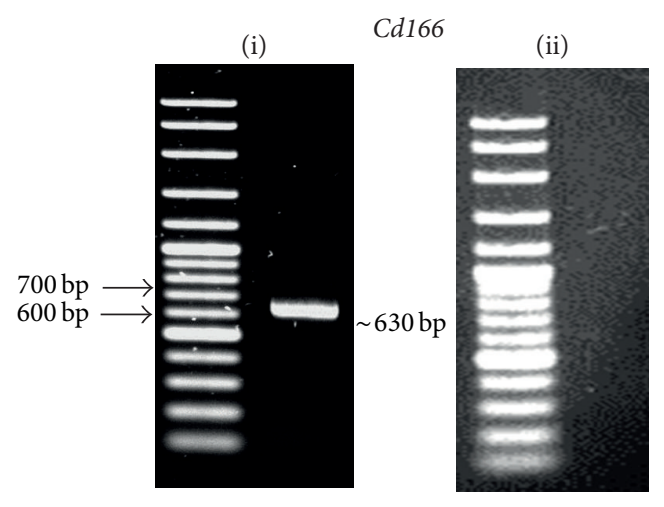

(i) Undifferentiated cells

(ii) Differentiated cells

(b)

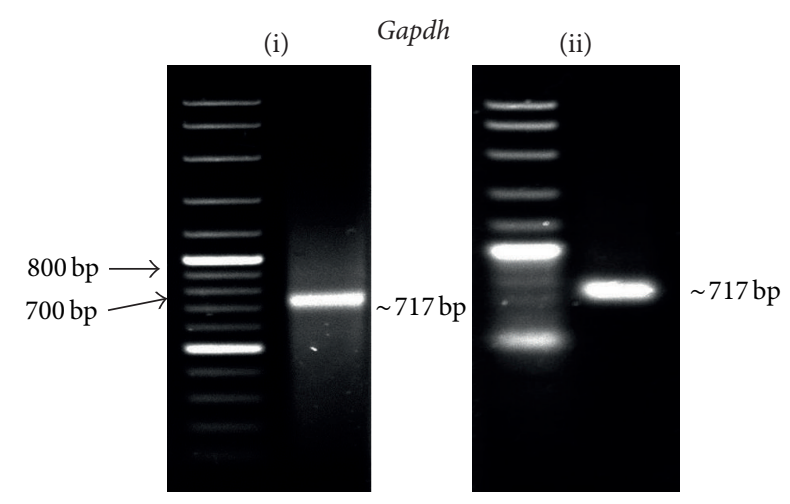

(i) Undifferentiated cells

(ii) Differentiated cells

(d)

Figure 2: Activation of mesenchymal stem cell markers. The activation of Cd146 ( 479 bp) (a) and Cd166 ( 630 bp) (b) was observed only in cells before differentiation, indicating that the cells were mesenchymal stem cells. Cd31 was inactivated before and after neuronal differentiation (c). Gapdh ( $717 \mathrm{bp})$, a housekeeping gene, was expressed before and after differentiation (d). Panel (i) is representing undifferentiated cells, that is, cells before neuronal differentiation, while panel (ii) is representing differentiated cells, that is, cells after neuronal differentiation.

cells. Statistical analysis showed a significant difference $(P<$ $0.05)$ in cell number between the two types of cells at days 3 and 5 of culture (Figure 5).

\section{Discussion}

The cells formed a fibroblast-like morphology during the fourth passage. Molecular analysis showing Cd146 and Cd166 amplicon but not $C d 31$ validated that the fibroblast-like cells were MSCs rather than hematopoietic stem cells. Cd146 and Cd166 are mesenchymal stem cell markers [36, 37]. Cd146 is an early mesenchymal stem cell marker expressed within dental pulp tissues [36]. Cd166 is a cell adhesion molecule that plays important roles in tight cell-to-cell interaction and in the regulation of MSCs differentiation [38]. While Cd166 is expressed in a wide variety of tissues, it is usually restricted to subsets of cells involved in processes of dynamic growth and/or migration, including neural development and immune response [39]. The amplicon of Gapdh found in DPSC both before and after differentiation indicated that Gapdh is expressed in both types of cells.

To confirm the differentiation of DPSCs to a neuronal phenotype and to demonstrate that this differentiation was not an artefact, three analyses were performed: morphological changes, expression of MAP2, and activation of neuronal markers. After 2 days of culture, most of the cells resembled multipolar neuron. However, some fibroblast-like cells with spread-out morphology were still observed in the population. We suggest that DPSCs changed gradually and differentiated into neuron-like cells after 5 days when cultured in serumand growth factor-free medium. DPSCs from various tissues differentiated into neuronal cells by displaying neuron morphology [40, 41], similar to our observations. Thus, 


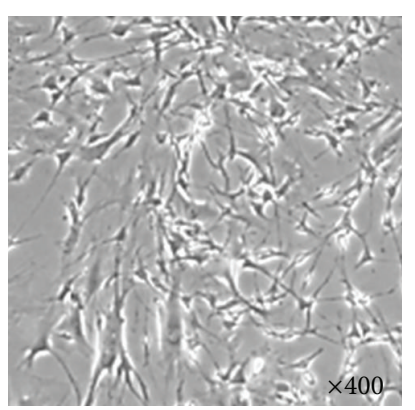

(a)

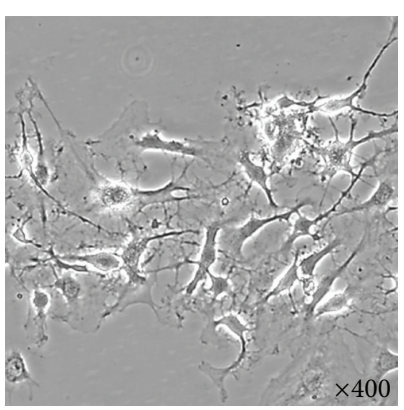

(b)

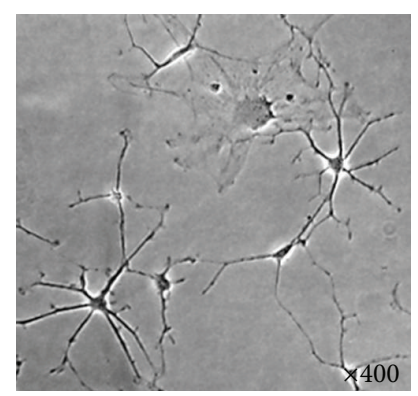

(c)

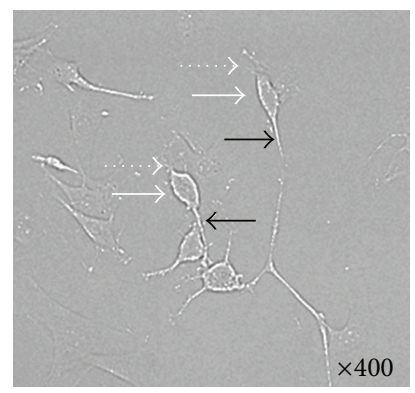

(d)

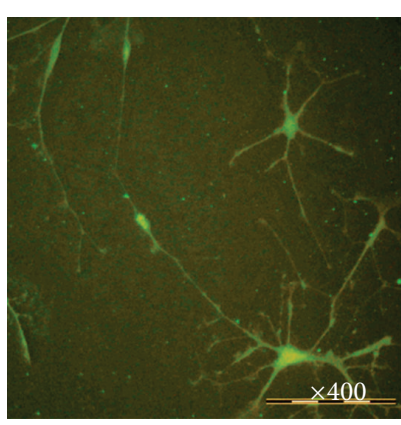

(e)

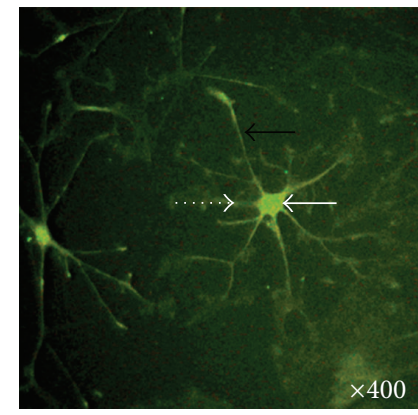

(f)

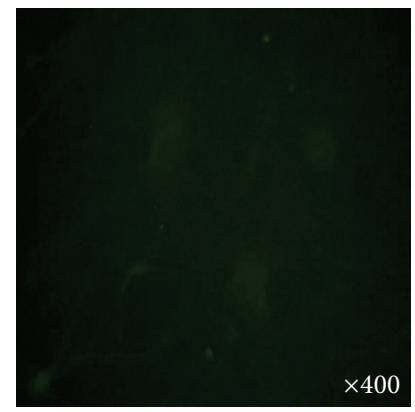

(g)

Figure 3: Characteristics of differentiated cells. Neuron-like cells appeared among the dental pulp stem cells ((a), (b)) 5 days after neuronal induction (c). The perikaryon, dendrites, and axons of neurons are indicated, respectively, by white arrows, open arrowheads, and black arrows (d). Immunofluorescence staining for neuron markers MAP2 was performed after 5 days of neuronal induction ((e), (f)). MAP2 marker was not detected in DPSCs without neuronal induction, that is, negative control (g).

morphological analysis indicated that DPSCs isolated from dental pulp tissue differentiated into neurons.

RT-PCR analysis showed the presence of a Nestin amplicon. Nestin is a neuron marker in adult rat and human brains [42]. Both Nestin and Tub3 were also used as markers to investigate neuronal differentiation in the hippocampus of mice after DPSC implantation [43]. The expression of both Nestin and Tub3 after differentiation indicated that the DPSCs differentiated into neuronal cells. Nestin is one of the intermediate filaments found in the cytoskeleton of vertebrate cells $[19,44]$. Nestin expression was used to track the proliferation, migration, and differentiation of neuronal stem cells. Tub3 is expressed in all eukaryotic cells. It contributes to microtubule stability in neuronal cell and plays a role in axonal transport. In the present study, Tub3 was activated after 5 days of neuronal differentiation. Gapdh was used as a positive control both before and after differentiation. Gapdh is a housekeeping gene which has always been activated by all mammalian cells whether by undifferentiated or differentiated cells [45]. It was used to determine the RNA quality of isolated DPSCs and to normalize the levels of mRNAs. A Gapdh amplicon was found in cells both before and after differentiation, indicating that Gapdh remains activated in both types of cells.

Nestin activation was increased during neuronal differentiation. Nestin is known to be expressed within fibrous dental pulp tissue, however, its expression continued to be detected by the majority of DPSCs following neuronal induction; that is, expression of Nestin was increased when cells differentiated into neuron [28]. MAP2 and Tub3 are expressed only after neuronal differentiation and are therefore utilized as markers of mature neuronal cells during the final stages of growth [46-48]. MAP2-positive neuronal cells have been shown to be adult neuronal cells produced by neuronal induction. Varied expression of Nestin in several cell types such as hair follicle stem cells, pericytes, endothelial cells, myofibroblasts, and pancreatic fibroblasts makes Nestin not specific to neuron [23-26]. However, combination of Nestin expression together with the expression of other neural markers, that is, Tub3 and MAP2, can support neuronal differentiation. In addition, characterization of the neuronlike cell by morphological analysis also showed a positive result.

While growth factors such as FGF and retinoic acid have been employed in previous studies, neuronal induction was induced in the present study solely by excluding serum and growth factors from the complete medium. Our observations on Tub3 and Nestin activation, neuron-like cells morphology, and MAP2 expression provide evidence for the directed differentiation of mouse dental pulp stem cells into neuronlike cells in serum- and growth factor-free medium.

The proliferation of the differentiated cells continued although their growth rate was lower than that of the control group. Theoretically, proliferation and differentiation of cells cannot occur simultaneously. The signalling cues that coordinate these two processes are largely unknown. However, cell differentiation and proliferation are regulated simultaneously 


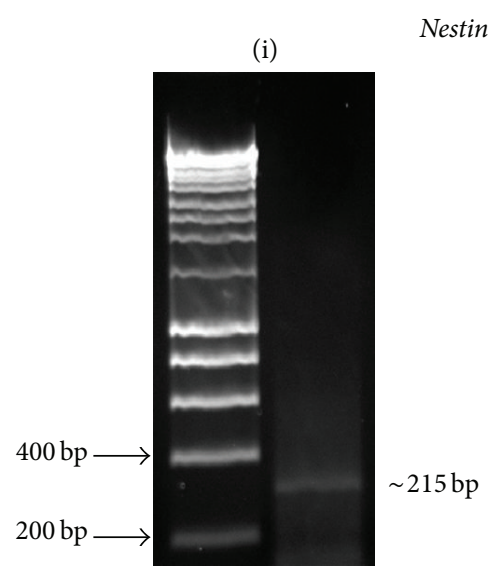

(i) Undifferentiated cells

(ii) Differentiated cells (ii)

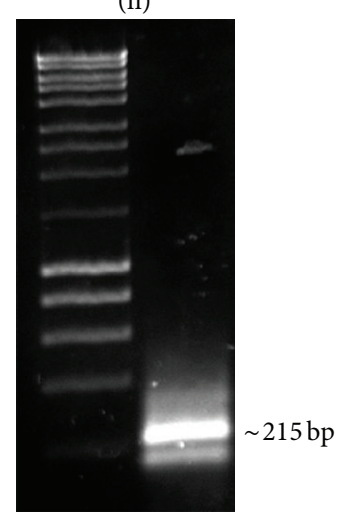

(i)

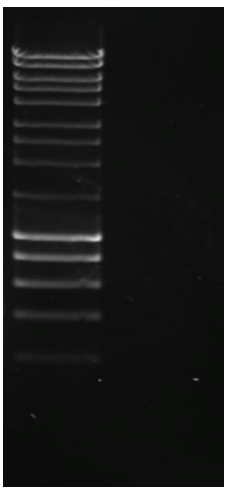

Tub3

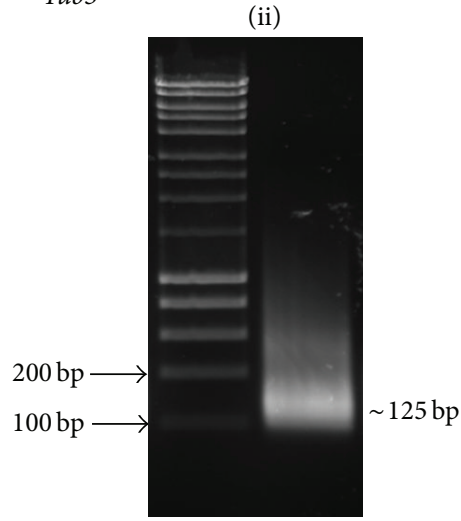

(i) Undifferentiated cells

(ii) Differentiated cells

(b)

(i)

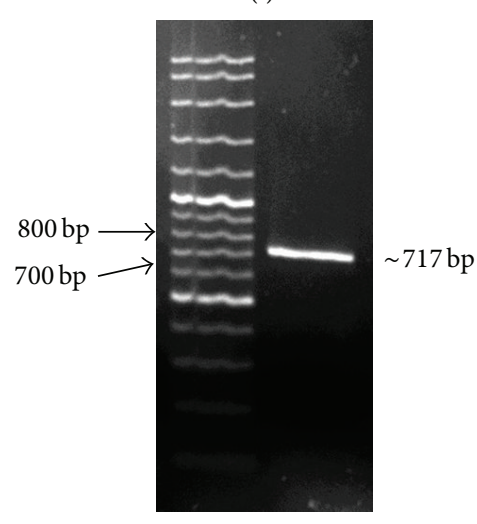

(ii)

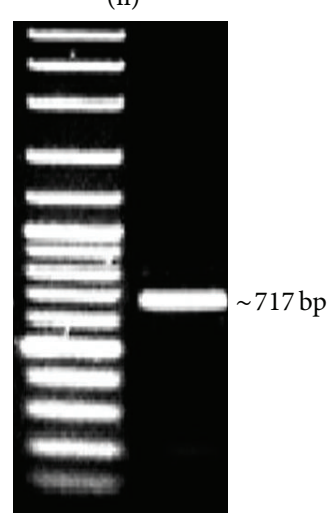

(i) Undifferentiated cells

(ii) Differentiated cells

(c)

Figure 4: Activation of specific neuronal markers.The activation of Nestin ( 215 bp) (a) and Tub3 ( 125 bp) (b) indicated that the cells had differentiated into neurons. Gapdh ( 717 bp), a housekeeping gene, was activated before and after differentiation (c). Panel (i) is representing undifferentiated cells, that is, cells before neuronal differentiation, while panel (ii) is representing differentiated cells, that is, cells after neuronal differentiation.

but independently, that cells often start differentiating long before they stop dividing, and that the initiation of differentiation is not restricted to any particular segment of the cell cycle $[49,50]$. In the present study, differentiated cells began to divide slowly after 24 hours of culture and continued until the end of the differentiation period, suggesting that the cells undergo differentiation immediately after neuronal differentiation has been induced. Although the number of cells increased upon the induction of differentiation, the cells subsequently showed a growth rate reduction and focused on the differentiation process.

Capabilities of adult stem cells to differentiate into cells from different germ layers or cell lineages are known as transdifferentiation. Stem cells from bone marrow which originated from mesoderm were shown to be able to differentiate into liver, lung, gastrointestinal tract, and skin cells which derived from endoderm and mesoderm [51]. Peripheral blood stem cells (hematopoietic stem cells) also were found able to differentiate into mature cells which were not originated from hematopoietic cells such as liver, skin epithelial, and gastrointestinal tract cells [52]. Changes that occur to cell microenvironments such as addition of certain growth or differentiation factors during in vitro cell culture were found to be able to induce transdifferentiation [53]. Deletion of serum also contributed to this transdifferentiation since addition of serum in the medium allowed growth 


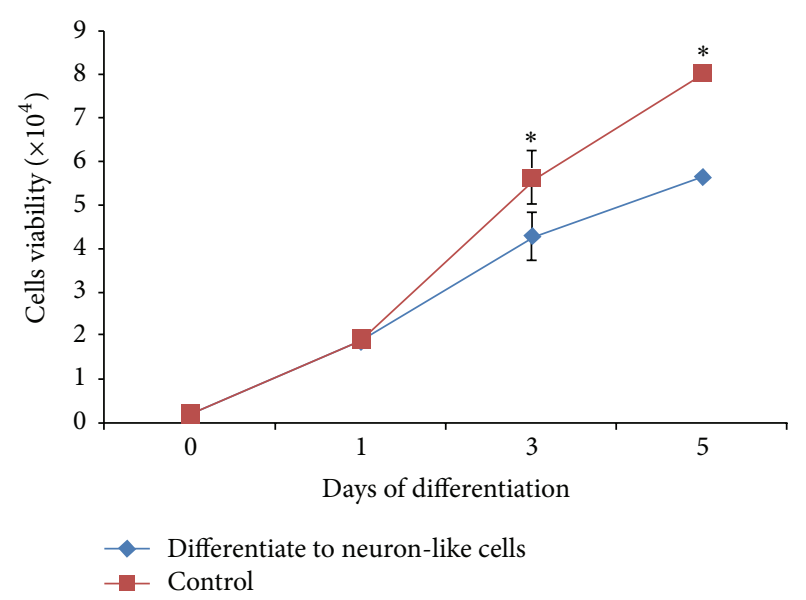

FIGURE 5: Viability of cells during directed differentiation. The viability of control (undifferentiated cells cultured in complete medium) versus differentiated cells cultured in serum- and growth factor-free medium. The numbers of both control and differentiated cells were significantly increased upon differentiation compared with day 0 of culture. The results are summarized as the mean \pm SD. Statistical significance was determined using SPSS program version 16.0.2. ${ }^{*}$ Statistical analysis showed significant differences $(P<0.05)$ of viable cells at days 3 and 5 of culture as compared to control.

and maintenance of cells and prevented embryonic stem cells differentiation into neuronal cells [54]. In this study, the absence of serum and growth factors during culture may lead to DPSCs transdifferentiation into neuron-like cells.

\section{Conclusions}

Dental pulp stem cells are induced to differentiate into neuronal cells when cultured in serum- and growth factor-free medium.

\section{Authors' Contribution}

Shahrul Hisham Zainal Ariffin is head of this project. He designed the experiment and characterized the cell lines. Shabnam Kermani performed the experiments. Intan Zarina Zainol Abidin analyzed the data and corrected and rewrote the paper. Rohaya Megat Abdul Wahab designed the experiment and analyzed the data. Zulham Yamamoto wrote the paper. Sahidan Senafi and Zaidah Zainal Ariffin analyzed the data and corrected the paper. Mohamad Abdul Razak designed the experiment and the research approaches. All authors have read and approved the paper.

\section{Acknowledgments}

This research project was funded by Grants FRGS/1/2011/SG/ UKM/02/13 and ERGS/1/2012/SKK11/UKM/02/5 from the Ministry of Higher Education of Malaysia and UKM-DLP2012-025, UKM-DLP-2012-001, and DPP-2013-024 from Universiti Kebangsaan Malaysia.

\section{References}

[1] I. Kerkis, A. Kerkis, D. Dozortsev et al., "Isolation and characterization of a population of immature dental pulp stem cells expressing OCT-4 and other embryonic stem cell markers," Cells Tissues Organs, vol. 184, no. 3-4, pp. 105-116, 2007.

[2] E. Javazon, J. Tebbets, and K. Beggs, "Isolation, expansion and characterization of murine adult bone marrow derived mesenchymal stem cells," Blood, vol. 102, pp. 180B-181B, 2003.

[3] S. H. Zainal Ariffin, I. Z. Zainol Abidin, M. D. Yazid, and R. Megat Abdul Wahab, "Differentiation analyses of adult suspension mononucleated peripheral blood cells of Mus musculus," Cell Communication and Signaling, vol. 8, article 29, 2010.

[4] M. D. Yazid, S. H. Zainal Ariffin, S. Senafi, Z. Zainal Ariffin, and R. Megat Abdul Wahab, "Stem Cell Heterogeneity of mononucleated cells from murine peripheral blood: molecular analysis," TheScientificWorldJOURNAL, vol. 11, pp. 2150-2159, 2011.

[5] M. D. Yazid, S. H. Z. Ariffin, S. Senafi, M. A. Razak, and R. M. A. Wahab, "Determination of the differentiation capacities of murines'; primary mononucleated cells and MC3T3-E1 cells," Cancer Cell International, vol. 10, article 42, 2010.

[6] T. Hermida-Gomez, I. Fuentes-Boquete, M. J. Gimeno-Longas et al., "Quantification of cells expressing mesenchymal stem cell markers in healthy and osteoarthritic synovial membranes," Journal of Rheumatology, vol. 38, no. 2, pp. 339-349, 2011.

[7] Y. Sumita, S. Tsuchiya, I. Asahina, H. Kagami, and M. J. Honda, "The location and characteristics of two populations of dental pulp cells affect tooth development," European Journal of Oral Sciences, vol. 117, no. 2, pp. 113-121, 2009.

[8] C. Gandia, A. N. A. Armiñan, J. M. García-Verdugo et al., "Human dental pulp stem cells improve left ventricular function, induce angiogenesis, and reduce infarct size in rats with acute myocardial infarction," Stem Cells, vol. 26, no. 3, pp. 638645, 2008.

[9] A. Graziano, R. D’aquino, M. G. Cusella-De Angelis et al., "Scaffold's surface geometry significantly affects human stem cell bone tissue engineering," Journal of Cellular Physiology, vol. 214, no. 1, pp. 166-172, 2008.

[10] S. Gronthos, M. Mankani, J. Brahim, P. G. Robey, and S. Shi, "Postnatal human dental pulp stem cells (DPSCs) In Vitro and In Vivo," Proceedings of the National Academy of Sciences of the United States of America, vol. 97, no. 25, pp. 13625-13630, 2000.

[11] S. Shi, P. G. Robey, and S. Gronthos, "Comparison of human dental pulp and bone marrow stromal stem cells by cDNA microarray analysis," Bone, vol. 29, no. 6, pp. 532-539, 2001.

[12] B. Neuhuber, G. Gallo, L. Howard, L. Kostura, A. Mackay, and I. Fischer, "Reevaluation of In Vitro differentiation protocols for bone marrow stromal cells: disruption of actin cytoskeleton induces rapid morphological changes and mimics neuronal phenotype," Journal of Neuroscience Research, vol. 77, no. 2, pp. 192-204, 2004.

[13] G. Muñoz-Elías, D. Woodbury, and I. B. Black, "Marrow stromal cells, mitosis, and neuronal differentiation: stem cell and precursor functions," Stem Cells, vol. 21, no. 4, pp. 437-448, 2003.

[14] T. R. Brazelton, F. M. V. Rossi, G. I. Keshet, and H. M. Blau, "From marrow to brain: expression of neuronal phenotypes in adult mice," Science, vol. 290, no. 5497, pp. 1775-1779, 2000.

[15] A. J. Sloan and R. J. Waddington, "Dental pulp stem cells: what, where, how?" International Journal of Paediatric Dentistry, vol. 19, no. 1, pp. 61-70, 2009. 
[16] A. C. W. Zannettino, S. Paton, A. Arthur et al., "Multipotential human adipose-derived stromal stem cells exhibit a perivascular phenotype in vitro and in vivo," Journal of Cellular Physiology, vol. 214, no. 2, pp. 413-421, 2008.

[17] S. Gronthos, J. Brahim, W. Li et al., "Stem cell properties of human dental pulp stem cells," Journal of Dental Research, vol. 81, no. 8, pp. 531-535, 2002.

[18] C. A. Messam, J. Hou, and E. O. Major, "Co-expression of nestin in neural and glial cells in the developing human CNS defined by a human specific anti-nestin antibody," Experimental Neurology, vol. 161, no. 2, pp. 585-596, 2000.

[19] D. Guérette, P. A. Khan, P. E. Savard, and M. Vincent, "Molecular evolution of type VI intermediate filament proteins," $B M C$ Evolutionary Biology, vol. 7, article 164, 2007.

[20] C. Janke and M. Kneussel, "Tubulin post-translational modifications: encoding functions on the neuronal microtubule cytoskeleton," Trends in Neurosciences, vol. 33, no. 8, pp. 362372, 2010.

[21] L. Chang and R. D. Goldman, "Intermediate filaments mediate cytoskeletal crosstalk," Nature Reviews Molecular Cell Biology, vol. 5, no. 8, pp. 601-613, 2004.

[22] T. Tohyama, V. M. Lee, L. B. Rorke, M. Marvin, R. D. G. McKay, and J. Q. Trojanowski, "Nestin expression in embryonic human neuroepithelium and in human neuroepithelial tumor cells," Laboratory Investigation, vol. 66, no. 3, pp. 303-313, 1992.

[23] R. M. Hoffman, "The potential of nestin-expressing hair follicle stem cells in regenerative medicine," Expert Opinion on Biological Therapy, vol. 7, no. 3, pp. 289-291, 2007.

[24] J. P. Levesque, "A niche in a dish: pericytes support HSC," Blood, vol. 121, pp. 2816-2818, 2013.

[25] S. Suzuki, J. Namiki, S. Shibata, Y. Mastuzaki, and H. Okano, "The neural stem/progenitor cell marker nestin is expressed in proliferative endothelial cells, but not in mature vasculature," Journal of Histochemistry and Cytochemistry, vol. 58, no. 8, pp. 721-730, 2010.

[26] Y. Kishaba, D. Matsubara, and T. Niki, "Heterogeneous expression of nestin in myofibroblasts of various human tissues," Pathology International, vol. 60, no. 5, pp. 378-385, 2010.

[27] M. K. Lee, J. B. Tuttle, L. I. Rebhun, D. W. Cleveland, and A. Frankfurter, "The expression and posttranslational modification of a neuron-specific beta-tubulin isotype during chick embryogenesis," Cell Motility and the Cytoskeleton, vol. 17, no. 2, pp. 118-132, 1990.

[28] A. Arthur, G. Rychkov, S. Shi, S. A. Koblar, and S. Gronthose, "Adult human dental pulp stem cells differentiate toward functionally active neurons under appropriate environmental cues," Stem Cells, vol. 26, no. 7, pp. 1787-1795, 2008.

[29] N. Kalcheva, J. Albala, K. O’Guin, H. Rubino, C. Garner, and B. Shafit-Zagardo, "Genomic structure of human microtubuleassociated protein 2 (MAP-2) and characterization of additional MAP-2 isoforms," Proceedings of the National Academy of Sciences of the United States of America, vol. 92, no. 24, pp. 10894-10898, 1995.

[30] S. Kermani, K. Karbalaie, S. H. Madani et al., "Effect of lead on proliferation and neural differentiation of mouse bone marrowmesenchymal stem cells," Toxicology In Vitro, vol. 22, no. 4, pp. 995-1001, 2008.

[31] R. W. L. Lim and S. Halpain, "Regulated association of microtubule-associated protein 2 (MAP2) with Src and Grb2: evidence for MAP2 as a scaffolding protein," Journal of Biological Chemistry, vol. 275, no. 27, pp. 20578-20587, 2000.
[32] T. Doniach, "Basic FGF as an inducer of anteroposterior neural pattern," Cell, vol. 83, no. 7, pp. 1067-1070, 1995.

[33] D. P. Hill and K. A. Robertson, "Characterization of the cholinergic neuronal differentiation of the human neuroblastoma cell line LA-N-5 after treatment with retinoic acid," Developmental Brain Research, vol. 102, no. 1, pp. 53-67, 1997.

[34] V. Tropepe, M. Sibilia, B. G. Ciruna, J. Rossant, E. F. Wagner, and D. Van Der Kooy, "Distinct neural stem cells proliferate in response to EGF and FGF in the developing mouse telencephalon," Developmental Biology, vol. 208, no. 1, pp. 166-188, 1999.

[35] K. Guan, H. Chang, A. Rolletschek, and A. M. Wobus, "Embryonic stem cell-derived neurogenesis: retinoic acid induction and lineage selection of neuronal cells," Cell and Tissue Research, vol. 305, no. 2, pp. 171-176, 2001.

[36] M. Miura, S. Gronthos, M. Zhao et al., "SHED: stem cells from human exfoliated deciduous teeth," Proceedings of the National Academy of Sciences of the United States of America, vol. 100, no. 10, pp. 5807-5812, 2003.

[37] A. P. Croft and S. A. Przyborski, "Mesenchymal stem cells from the bone marrow stroma: basic biology and potential for cell therapy," Current Anaesthesia and Critical Care, vol. 15, no. 6, pp. 410-417, 2004.

[38] H. Fujiwara, K. Tatsumi, K. Kosaka et al., "Human blastocysts and endometrial epithelial cells express activated leukocyte cell adhesion molecule (ALCAM/CD166)," Journal of Clinical Endocrinology and Metabolism, vol. 88, no. 7, pp. 3437-3443, 2003.

[39] G. W. M. Swart, "Activated leukocyte cell adhesion molecule (CD166/ALCAM): developmental and mechanistic aspects of cell clustering and cell migration," European Journal of Cell Biology, vol. 81, no. 6, pp. 313-321, 2002.

[40] D. R. Martin, N. R. Cox, T. L. Hathcock, G. P. Niemeyer, and H. J. Baker, "Isolation and characterization of multipotential mesenchymal stem cells from feline bone marrow," Experimental Hematology, vol. 30, no. 8, pp. 879-886, 2002.

[41] L. Qian and W. M. Saltzman, "Improving the expansion and neuronal differentiation of mesenchymal stem cells through culture surface modification," Biomaterials, vol. 25, no. 7-8, pp. 1331-1337, 2004.

[42] M. L. Hendrickson, A. J. Rao, O. N. A. Demerdash, and R. E. Kalil, "Expression of nestin by neural cells in the adult rat and human brain," PLoS ONE, vol. 6, no. 4, Article ID e18535, 2011.

[43] A. H.C. Huang, B. R. Snyder, P.H. Cheng, and A. W. S. Chan, "Putative dental pulp-derived stem/stromal cells promote proliferation and differentiation of endogenous neural cells in the hippocampus of mice," Stem Cells, vol. 26, no. 10, pp. 2654-2663, 2008.

[44] L. Chang and R. D. Goldman, "Intermediate filaments mediate cytoskeletal crosstalk," Nature Reviews Molecular Cell Biology, vol. 5, no. 8, pp. 601-613, 2004.

[45] R. D. Barber, D. W. Harmer, R. A. Coleman, and B. J. Clark, "GAPDH as a housekeeping gene: analysis of GAPDH mRNA expression in a panel of 72 human tissues," Physiological Genomics, vol. 21, no. 3, pp. 389-395, 2005.

[46] M. Cristofanilli, S. Thanos, J. Brosius, S. Kindler, and H. Tiedge, "Neuronal MAP2 mRNA: species-dependent differential dendritic targeting competence," Journal of Molecular Biology, vol. 341, no. 4, pp. 927-934, 2004.

[47] C. B. Johansson, S. Momma, D. L. Clarke, M. Risling, U. Lendahl, and J. Frisén, "Identification of a neural stem cell in 
the adult mammalian central nervous system," Cell, vol. 96, no. 1, pp. 25-34, 1999.

[48] E. Karaoz, B. N. Dogan, A. Aksoy et al., "Isolation and in vitro characterisation of dental pulp stem cells from natal teeth," Histochemistry and Cell Biology, vol. 133, pp. 95-112, 2010.

[49] G. Brown, P. J. Hughes, and R. H. Michell, "Cell differentiation and proliferation-simultaneous but independent?" Experimental Cell Research, vol. 291, no. 2, pp. 282-288, 2003.

[50] H. Geng, R. Lan, G. Wang et al., "Inhibition of autoregulated TGFbeta signaling simultaneously enhances proliferation and differentiation of kidney epithelium and promotes repair following renal ischemia," American Journal of Pathology, vol. 174, no. 4, pp. 1291-1308, 2009.

[51] D. S. Krause, N. D. Theise, M. I. Collector et al., "Multi-organ, multi-lineage engraftment by a single bone marrow-derived stem cell," Cell, vol. 105, no. 3, pp. 369-377, 2001.

[52] M. Körbling, R. L. Katz, A. Khanna et al., "Hepatocytes and epithelial cells of donor origin in recipients of peripheral-blood stem cells," New England Journal of Medicine, vol. 346, no. 10, pp. 738-746, 2002.

[53] L. Yang, S. Li, H. Hatch et al., "In vitro trans-differentiation of adult hepatic stem cells into pancreatic endocrine hormoneproducing cells," Proceedings of the National Academy of Sciences of the United States of America, vol. 99, no. 12, pp. 8078-8083, 2002.

[54] M. Darmon, J. Bottenstein, and G. Sato, "Neural differentiation following culture of embryonal carcinoma cells in a serum-free defined medium," Developmental Biology, vol. 85, no. 2, pp. 463473, 1981 . 

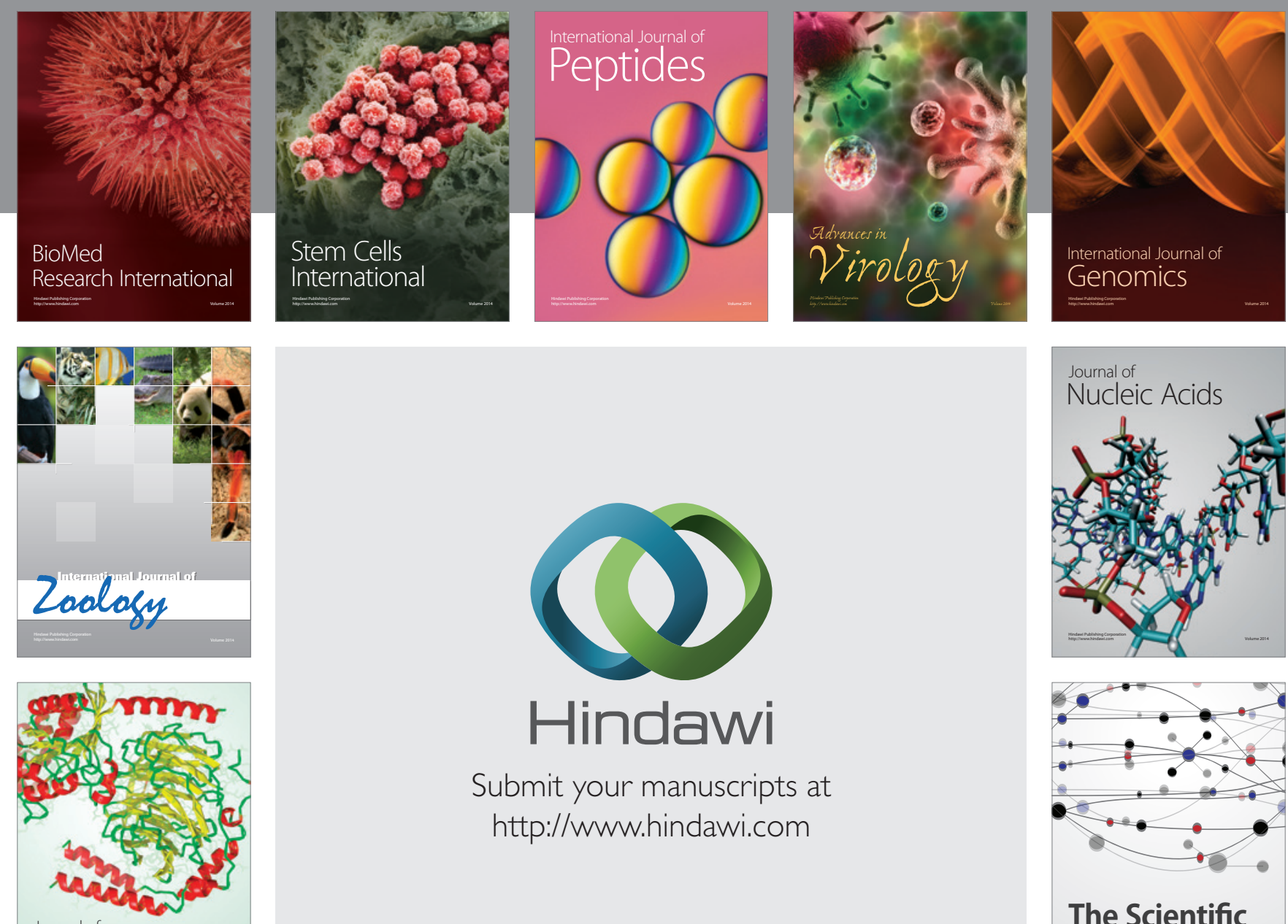

Submit your manuscripts at

http://www.hindawi.com

Journal of
Signal Transduction
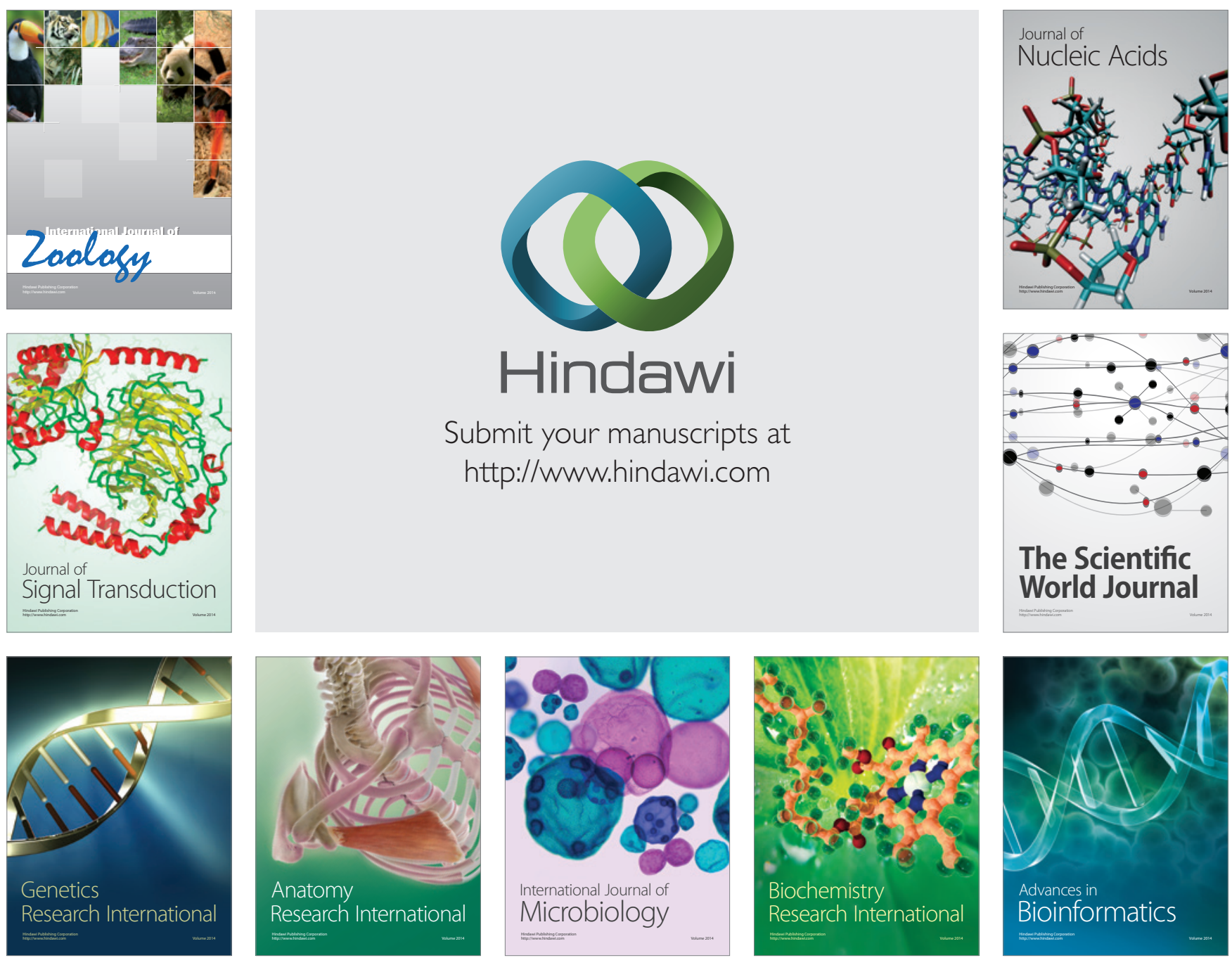

The Scientific World Journal
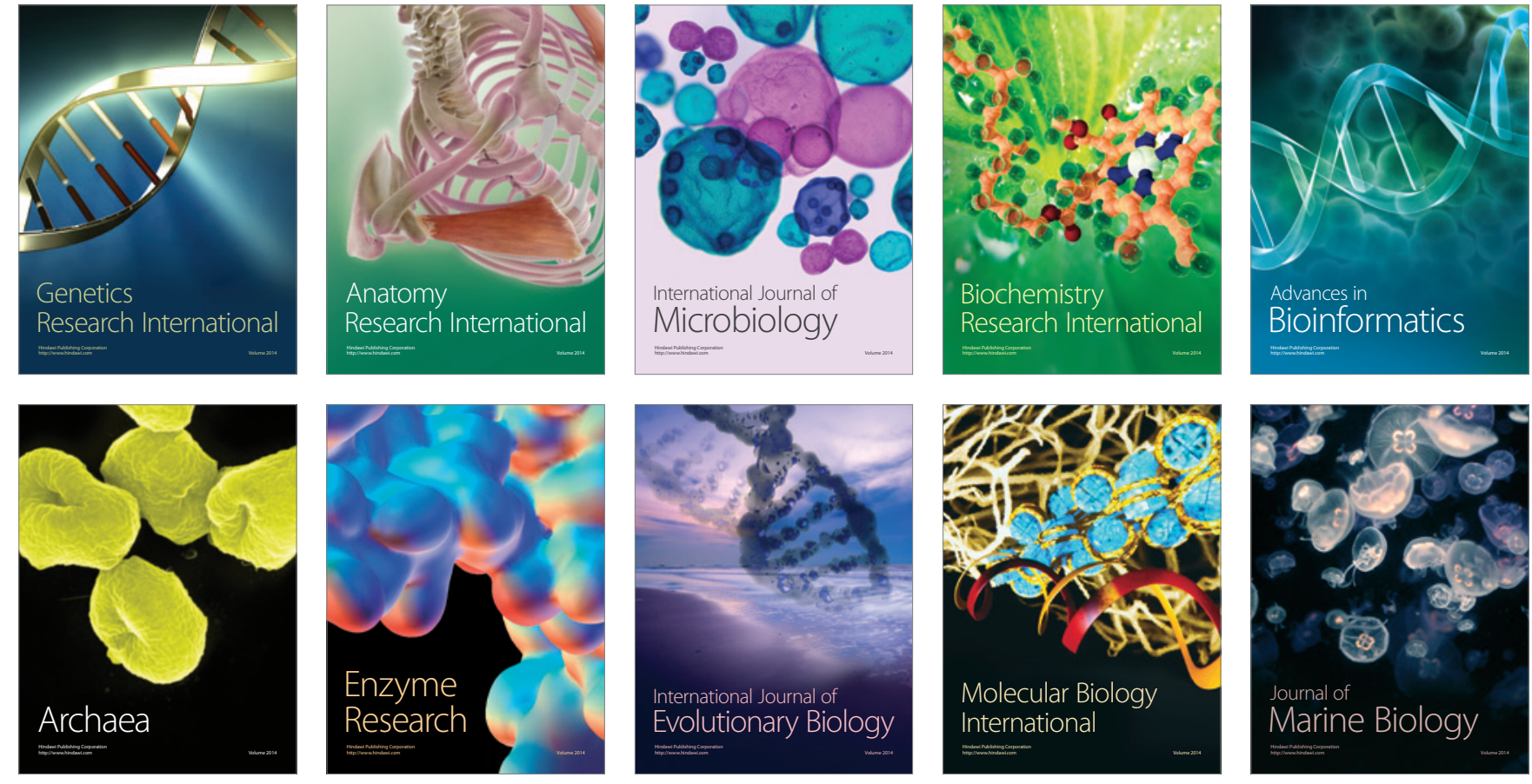